\title{
LINKING ERGONOMICS SIMULATION TO PRODUCTION PROCESS DEVELOPMENT
}

\author{
Salla Lind \\ Boris Krassi \\ Juhani Viitaniemi \\ Sauli Kiviranta \\ Juhani Heilala \\ Cecilia Berlin \\ Systems Engineering \\ Systems Engineering \\ VTT Technical Research Centre of \\ Finland \\ VTT Technical Research Centre of \\ Finland \\ Division of Production Systems \\ Chalmers University of Technology \\ Tampere, FI-33101, FINLAND \\ Espoo, FI-02044, FINLAND \\ Gothenburg, SE-41296, SWEDEN
}

\begin{abstract}
Production development can conflict with production ergonomics and management of environmental impacts. In this paper, we describe how ergonomics can be assessed in production system design by means of a joint simulation tool. The tool enables ergonomics and environmental impacts assessment in conjunction with production process development. The ergonomics sub-tool is based on a digital human model, which has been improved by introducing an updated data measurement system and neural network processing and inference functionality. The results will extend the new simulation modelling capabilities of the existing digital human model by increasing the motion prediction accuracy and providing freedom to model a multitude of task-related motions in a realistic way.
\end{abstract}

\section{INTRODUCTION}

Manual work and automation are the complementary elements in modern production systems. The increasing customization and shortening product lifecycle have led to smaller batch sizes and more product variants. The intelligence and adaptability of human workers make them the most flexible part of the production process. In this context, it is desirable to combine a human's flexibility with the accuracy, speed and force of the machine.

However, if ergonomics are neglected, the industrial conditions can expose the worker to excessive mental and physical stress. Manual work requires the worker to manage several different factors at the same time. Such factors can relate to safety, task and the working environment. (see e.g. Helin et al. 2007, Oedewald and
Reiman 2007). To harmonize the functions and task allocation between the human and the machine, various approaches, such as participatory design, can be applied (Vink et al. 1995, Vink et al. 2006, Rivilis et al. 2007).

In general, the required and feasible working postures, working locations, and working manoeuvres should be synchronized using simulation or analytical assessment. Besides physical matters, the organisational and cognitive loads have to be taken into account (Hollnagel and Woods 1999, Vicente 1999, Bisantz et al. 2003).

The static muscle stress and psychosocial load can be reduced by optimizing biomechanical and mental load, and taking into account workers' feedback (Wilson 1995, Westgaard and Winkel 1997). Therefore ergonomics should be included in to production process and equipment design (Laine et al. 2007, Malm et al. 2008).

When designing the production system, the human element becomes the most difficult part to model and simulate due to its inherent uncertainties and variations. Human performance modelling is one key subject in the analysis of level of automation. Siebers $(2004,2006)$ presents ideas on how to combine human performance modelling with discrete event simulation. It is important to understand human performance variation, because humans, unlike machines, cannot be modeled with an entirely deterministic logic.

In the Finnish-Swedish project SIMTER, we are developing an integrated simulation tool helping to maximize production efficiency and to balance manual and automated work subject to ergonomics constraints. The tool examines ergonomics and safety as a part of production process optimization. In this process, we employ a digital human model (DHM) "OSKU" (see Helin et al. 2007), a digital human model developed for 


\section{Lind, Krassi, Viitaniemi, Kiviranta, Heilala, and Berlin}

participatory production design which relies on a database of measured and recorded real human motions. This paper presents our efforts in improving OSKU and extending it to be a part of a production system design tool.

\section{BACKGROUND}

Developing ergonomics in early stages of production system design is increasingly recognized as an essential step towards achieving healthy and sustainable production systems. According to Laitila (2005), the capacity of digital human modeling (DHM) to assess ergonomics has increased significantly in recent years. As a result, DHM tools are increasingly used to identify and steer clear of potentially harmful working postures, forces and durations which can lead to work-related musculoskeletal disorders these in turn can result in company costs for worker replacement, compensation and rehabilitation (Kuorinka and Forcier 1995). Also, recent research by Falck (2007) demonstrates a relationship between poor ergonomics and reduced product quality, and emphasizes an imperative need for a holistic approach to ergonomics development. Subsequently, ergonomics development in parallel to other aspects of production planning can lead to economical gains for companies in terms of more efficient task allocation, reduced costs for staff turnover or sick-leave absenteeism (e.g. Munck-Ulfsfält et al. 2003), and prevention of potential reduced-quality production caused by poor workplace ergonomics (Falck 2007). This is the rationale for developing the SIMTER tool.

In analyzing and developing production ergonomics, a number of analysis methods can be applied. Such methods are, for example, task analysis (Hackos and Redish 1998, Stanton 2006), cognitive work analysis (Vicente 1999), contextual design (Beyer and Holzblatt 1999), usability testing (Nielsen 1993), heuristic usability evaluations (Nielsen 1993), ergonomics analyses (Karhu, Kansi, and Kuorinka 1977), and participatory design (Muller and Kuhn 1993). In the SIMTER tool, cognitive ergonomics could be included using e.g. task analysis, link analysis, check lists, questionnaires or visual/aural simulations (Hollnagel and Woods1999, Vicente 1999, Stanton 2006).

The SIMTER tool will allow the production engineer to gain insight into the ergonomic impact of the production system by means of human simulation within the production model. It is known that both physical and cognitive aspects of ergonomics affect the humans' ability to perform the job correctly and efficiently, while maintaining health and safety. But within this area, the primary focus of the SIMTER tool is physical ergonomics. The tool is planned to be able to measure task duration and to compare results with ergonomics indexes (e.g. NIOSH WPG 1981, Waters et al. 1993, Snook and Ciriello 1991, Liberty Mutual 2007, OSHA 2006, Garg, Chaffin, and
Herrin 1978). It will also enable reach, field of view and other physical factors analyses, including occupational hygiene factors such as temperature, noise and lighting. The possibilities of covering these aspects are plausible, and many of these aspects have already been implemented in the OSKU tool (Helin et al. 2007). The tool, featuring basic human simulation, is the starting point for SIMTER's ergonomics dimension.

The development process of OSKU proceeded as described below. First, we improve the way the database is recorded to combine information on anthropometric parameters of the human and the associated motions (joint values) for a multitude of tasks. Second, we increase the resolution of motion capture, so that the database can use either fixed points or free points in space. Third, we implement interpolation between recorded points with nonlinear data-based mapping algorithms, e.g. AdaptiveNetwork-Based Fuzzy Inference System (ANFIS). Fourth, we enable analysis and application combined motions of upper limbs, head, neck, and torso. This allows realistic reach and field of view analyses.

The SIMTER ergonomics sub-tool gives a realistic image of modelling a human task as the tool is based on real human motions taking into account anthropometric variations. These directions, which are in line with other research groups' work (e.g. Chaffin 2007, Broberg 2007), create the basis for simulating ergonomics the context of production design jointly with other production process parameters.

A joint simulation system supports the "Design for All" (DfA) principle that merges usability, accessibility, liberty, and barrier-freeness of environments, products and services to achieve sustainable and robust solutions (Saito 2006). Most system designers and engineers have to consider ergonomics from early steps in the product development process (Broberg 2007). Digital human models have to be implemented early to support engineers in their daily development work (Kaasinen and Norros 2007, Chaffin 2007, Nieminen 2004, Määttä 2007, Helin et al. 2007).

Several common and validated methods for evaluating the ergonomics of working postures are employed in OSKU and will be inherited in the SIMTER tool. Such methods include RULA (McAtamney and Corlett 1991), OWAS (Karhu, Kansi, and Kuorinka 1977), and ERGOKAN (Määttä 1994). RULA (Rapid Upper Limb Assessment) is a survey method for investigating biomechanical and postural loading on the upper body, with particular attention to neck, trunk and upper limbs. OWAS (Ovako Working Posture Analysing System) identifies and evaluates potentially harmful working postures using a scoring system. It can reveal the frequency and relative proportion of time spent in potentially harmful postures. Finally, ERGOKAN combines RULA and OWAS. 


\section{METHODS}

For the ergonomics sub-tool development, we apply two main methods. First, we gather background information from literature and interviews at partner companies in Finland and Sweden (see Lind et al. 2008). The industrial partner companies represent machine building, automotive and chemical industries.

Second, we have continued the work with OSKU (Helin et al. 2007) by improving the data collection, processing, and inference techniques. The primary aim of the OSKU tool is to develop a digital human model that enables ergonomics assessment in industrial environments and tasks. The improvement is achieved by applying neural networks for filtering raw data, motion spatial and temporal non-linear interpolation, and statistical interval estimation of motion trajectory and duration. The measurements are to be conducted using motion tracking system, where the sensors will be attached to hands, head and the sitting point. The recorded movements will include upper limb tracks from the sitting and standing positions. The motion data is utilized to train and validate the neural network. The purpose of the network is to predict humanlike motions for arbitrary starting and ending points without relying on a fixed-grid motion database. Utilising the new motion prediction extends the simulation modelling capabilities of the OSKU tool by extending the motion prediction accuracy and giving freedom to model all task-related motions in a realistic way. Moreover, the posture, link and task analyses will be calculated according to these motions.

\section{RESULTS}

The interview results indicated that the companies perceived problems due to challenging work tasks, such as welding in confined spaces. To improve production, jointly with ergonomics improvement, a digital human model can be applied to simulate and optimize the work sequence and techniques.

The hardware and software for data collection has been improved by employing Virtools software (see http://www.virtools.com/) allowing flexible data collection in a variety of usage scenarios: pick-and-place, welding, light assembly and office work. For the measurements, we designed a data glove to increase the precision of motion duration measurements and to automate the data collection process. Thus, the subject can perform measurements without an assistant. As the motion tracking system bases on magnetic field, the measurement were carried using all wooden custom-made furniture to prevent electromagnetic interference shown in Figure 1.

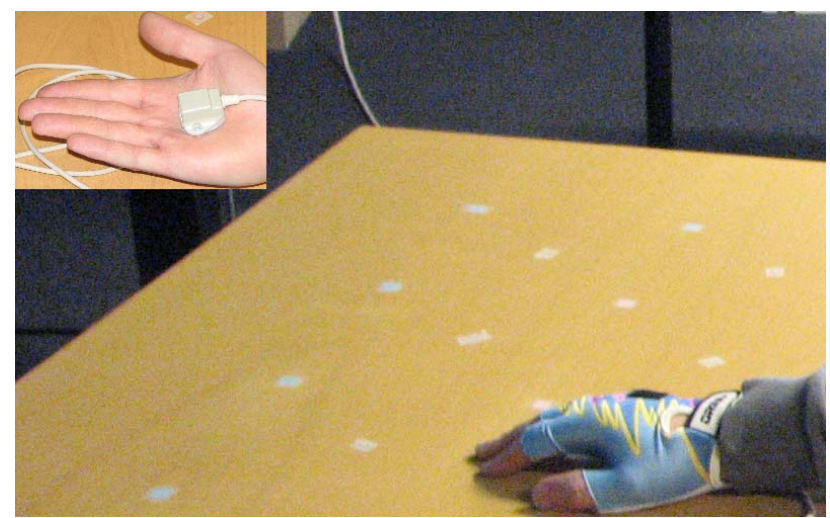

Figure 1: An example of motion data collection.

The network has been prototyped in Matlab (http://www.mathworks.com) neural network toolbox and it is now complete to process 3D data for six sensors (filtering and interpolating in 18 dimensions). The data collection for the network training and validation is being carried out. The parameters of the trained and validated network will be used on Visual Components platform, merging motion visualization, production simulation and ergonomics analyses. An example of motions predicted with the network is shown in Figure 2.

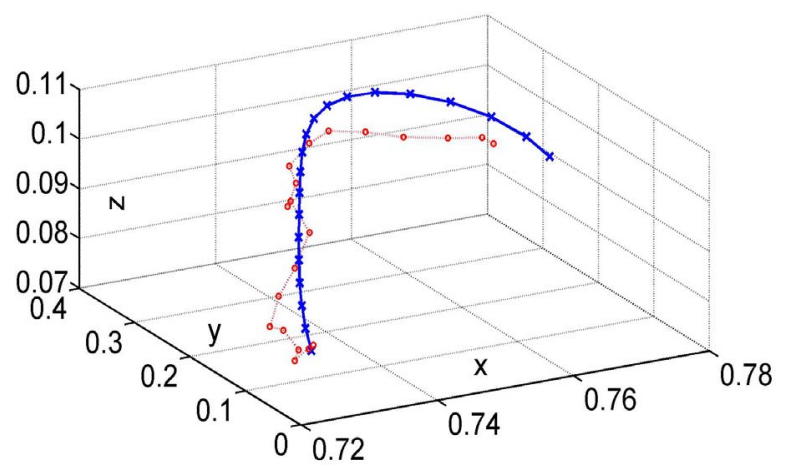

Figure 2: An example of motion prediction.

The dotted line represents the noisy validation data, whereas the solid line indicates the predicted interpolated motion. The discrepancy between the two is about 1-2 centimeters, which is even more precise than the motion tracking system's precision (5-7 centimeters) due to averaging over an ensemble of trajectories. An example of applying the OSKU tool into production simulation case is shown in Figure 3. 


\section{Lind, Krassi, Viitaniemi, Kiviranta, Heilala, and Berlin}

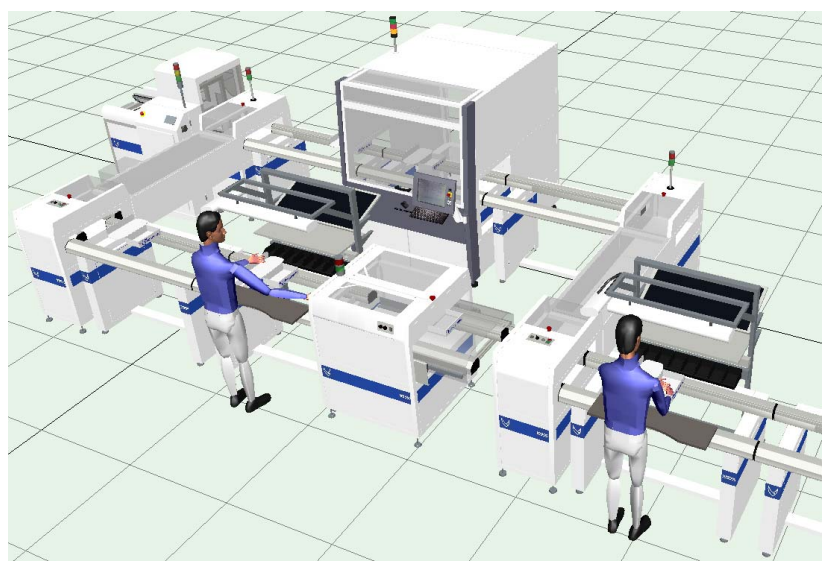

Figure 3: An example of OSKU tool applied into production simulation case; a given task to check, do assembly and follow near by machine's operations.

As a result from improvements in OSKU, the ergonomics sub-tool enables accurate simulation of human motions and the cycle times in a preferred set of tasks for which the network is trained.

\section{DISCUSSION AND CONCLUSIONS}

The SIMTER tool aims to integrate three complementary dimensions of production system design: ergonomics, environmental impacts, and level of automation. When integrating the sub-tools, the biggest issue is identifying the set of shared variables and compatible performance metrics. In comparison to production optimization and environmental impact, as well as ergonomics and production optimization, which are easy to link and quantify, the relation between environmental impacts and ergonomics are more elusive and hard to quantify. The difficulty comes from, for example, incompatible metrics (ethical issues are difficult to express in monetary terms) and differences in time scales (shortand long terms costs and effects). The connection between ergonomics and environmental impacts is an open, fundamental question.

Along with the refinement of sub-tools, part of the future work will be showing feasibility and value of the integrated tool in practice. The integrated SIMTER tool will be developed to enable even more detailed and balanced analyses of production systems in compliance with the sustainable development paradigm (see also Heilala et al. 2008/submitted).

This paper has described the ongoing work of developing an integrated simulation tool, where ergonomics simulation is considered an essential part of production process development. The results indicate that there is a demand for this kind of joint simulation tool.
Moreover, the implementation work has indicated that such integration of sub-tools is technically feasible.

\section{ACKNOWLEDGEMENTS}

The authors wish to acknowledge the financial support received from the Finnish Funding Agency for Technology and Innovation (TEKES), VINNOVA (Swedish Agency for Innovation Systems), VTT, Finnish and Swedish industry.

\section{REFERENCES}

Beyer, H., and K. Holtzblatt. 1999. Contextual Design. Interactions 6:32-42.

Bisantz, A.M., E. Roth, B. Brickman, L.L. Gosbee, L. Hettinger, J. McKinney. 2003. Integrating cognitive analyses in a large-scale system design process. International Journal of Human-Computer Studies 58(2):177-206.

Broberg, O. 2007. Integrating Ergonomics into Engineering: Empirical Evidence and Implications for the Ergonomists. Human Factors and Ergonomics in Manufacturing 17(4):353-366.

Chaffin, D.B. 2007. Human Motion Simulation for Vehicle and Workplace Design. Human Factors and Ergonomics in Manufacturing 17(5):475-484.

Falck, A.-C. 2007. Virtual and Physical Methods for Efficient Ergonomics Risk Assessments - A Development Process for Application in Car Manufacturing. Thesis. Chalmers University of Technology, Göteborg.

Garg, A., D.B. Chaffin, and G.D. Herrin. 1978. Prediction of Metabolic Rates for Manual Materials Handling Jobs. American Industrial Hygiene Association Journal 39(8).

Hackos, J.T., and J.C. Redish. 1998. User and Task Analysis for Interface Design. John Wiley and Sons.

Heilala J., S. Vatanen, J. Montonen, H. Tonteri, B. Johansson, J. Stahre, S. Lind. 2008. Simulation-Based Sustainable Manufacturing System Design. In Proceedings of the 2008 Winter Simulation Conference, ed. S. J. Mason, R. Hill, L. Moench, and O. Rose. (Submitted).

Helin, K., J. Viitaniemi, S. Aromaa, J. Montonen, T. Evilä, S-P. Leino, T. and Määttä. 2007. OSKU Digital Human Model in the Participatory Design Approach. A New Tool to Improve Work Tasks and Workplaces. VTT Working Papers VTT-WORK-83.

Hollnagel, E., D.D. Woods. 1999. Cognitive Systems Engineering: New wine in new bottles. International Journal of Human-Computer Studies 51(2):339-356. 
Kaasinen, E., and L. Norros. 2007. Älykkäiden ympäristöjen suunnittelu - Kohti ekologista systeemiajattelua [Design of Intelligent, Smart Environments - Towards Ecological System Thinking]. Teknologiateollisuus, Helsinki.

Karhu, O., P. Kansi, and I. Kuorinka. 1977. Correcting Working Postures in Industry: A Practical Method for Analysis. Applied Ergonomics 8(4):199-201.

Kuorinka, I., and L. Forcier, (ed.). 1995. Work Related Musculoskeletal Disordes (WMSDs): A Reference Book for Prevention. Taylor and Francis, London.

Laine, E., T. Malm, J. Latokartano. 2007. Human and industrial robot cooperation - technologies and practical examples. In Proceedings of 5th International Conference Safety Of Industrial Automated Systems. SIAS 2007, 397-402. Tokyo, Japan.

Laitila, L., 2005. Datormanikinprogram om verktyg vid arbetsplatsutformning - En kritisk studie av programanvändning. Thesis. Luleå Technical University, Luleå.

Liberty Mutual. 2007. Liberty Mutual Manual Materials Handling Tables. Available via $<$ http://libertymmhtables.libertymutual.com/CM_LM TablesWeb $>$ [accessed September 21, 2007]

Lind, S., B. Krassi, B. Johansson, J. Viitaniemi, J. Heilala, J. Stahre, S. Vatanen, Å Fasth, and C. Berlin. 2008. SIMTER: A Production Simulation Tool for Joint Assessment of Ergonomics, Level of Automation and Environmental Impacts. In The 18th International Conference on Flexible Automation and Intelligent Manufacturing (FAIM 2008).

Malm, T., J. Viitaniemi, I. Marstio., S. Toivonen, J. Koskinen, O. Venho, T. Salmi, E. Laine, J. Latokartano. 2008. Vuorovaikutteisen robotiikan turvallisuus [Safety of Interactive Robotics]. Suomen Robotiikkayhdistyksen julkaisusarja, Suomen Robotiikkayhdistys Ry, Helsinki.

McAtamney, L., and E.N. Corlett. 1993. RULA: A Survey Method for the Investigation of Work-related Upper Limb Disorders. Applied Ergonomics 24(2):91-99.

Muller, M.J., and S. Kuhn. 1993. Participatory Design. Communications of the ACM 36:24-28.

Munck-Ulfsfält, U., A. Falck, A. Forsberg., C. Dahlin, A. Eriksson. 2003. Corporate ergonomics programme at Volvo Car Corporation. Applied Ergonomics 34:1722.

Määttä, T. 1994. Analysing Working Postures Using ERGOKAN-method. An Example of Packing Work at a Bakery. In Proceedings of the 12th Triennial Congress of International Ergonomics Association, 351-353. Toronto, Canada.

Määttä, T. 2007. Human Virtual Environments in Machinery Safety Analysis and Participatory
Ergonomics. Human Factors and Ergonomics in Manufacturing 17(5):435-443.

Nielsen, J. 1993. Usability Engineering. Academic Press, Boston.

Nieminen, M. 2004. Information Support for UserOriented Development Organisation - Considerations Based on the Construction and Evaluation of Knowledge Storage. Dissertation thesis, Helsinki University of Technology Department of Computer Science and Engineering. Available via $<$ http://lib.tkk.fi> [access June 16, 2008]

NIOSH WPG. 1981. Work Practices Guide for Manual Lifting. NIOSH Technical Report No. 81-122. U.S. Department of Health and Human Services. National Institute for Occupational Safety and Health, Cincinnati, Ohio 45226, USA.

Oedewald, P. and Reiman, T. 2007. Special characteristics of safety critical organizations. Work psychological perspective. VTT Publications 633. Espoo.

OSHA 2006. US Department of Labor. Occupational Safety and Health Administration. OSHA Technical Manual (OTM). Directive number: TED 1-0.15A. Section VII: Ergonomics, Chapter 1. Back disorders and injuries.

Rivilis, I., Van Eerd, D., Cullen, K., Cole, D.C., Irwin, E., Tyson, J., Mahood, Q. 2008. Effectiveness of participatory ergonomic interventions on health outcomes. Applied Ergonomics 39(3):342-358.

Saito, Y. 2006. Awareness of Universal Design Among Facility Managers in Japan and the United States. Automation in Construction 15(4):462-478.

Siebers, P.O. 2006. Worker Performance Modeling in Manufacturing Systems Simulation. Chapter in J-P. Rennard (Eds.) Handbook of Research on Nature Inspired Computing for Economy and Management. Pennsylvania:Idea Group Publishing.

Siebers P.O. 2004. The Impact of Human Performance Variation on The Accuracy of Manufacturing System Simulation Models. Cranfield University, School of Industrial and Manufacturing Science. $\mathrm{PhD}$ Thesis 2004. Available via $<$ www.cs.nott.ac.uk/ pos/\#Publications $>$ [access June $16,2008]$

Snook, S.H. and Ciriello, V.M. 1991. The Design of Manual Handling Tasks: Revised Tables of Maximum Acceptable Weights and Forces. Ergonomics 34(9):1197-1213.

Stanton, N. 2006. Hierarchical task analysis: Developments, applications, and extensions. Applied Ergonomics 37(1):55-79.

Vicente, K.J. 1999. Cognitive Work Analysis. Toward Safe, Productive, and Healthy Computer-Based Work. Lawrence Erlbaum.

Vink, P., Peeters, M., Grundemann, R.W.M., Smulders, P.G.W., Kompier, M.A.J., Dul, J. 1995. A 
participatory ergonomics approach to reduce mental and physical workload. International Journal of Industrial Ergonomics 15(5):389-396.

Vink, P., E.A. Koningsveld, J.F. Molenbroek. 2006. Positive outcomes of participatory ergonomics in terms of greater comfort and higher productivity. Applied Ergonomics 37(4):537-546.

Westgaard, R.H., J. Vinkel. 1997. Ergonomic intervention research for improved musculoskeletal health: A critical review. International Journal of Industrial Ergonomics 20(6):463-500.

Wilson, J.R. 1995. Solution ownership in a participative work redesign - the case of a crane control room. International Journal of Industrial Ergonomics 15(5):329-344.

Waters, T.R., V. Putz-Anderson, A. Garg, and L.J. Fine. 1993. Revised NIOSH Equation for the Design and Evaluation of Manual Lifting Tasks. Ergonomics 36(7):749-776.

\section{AUTHOR BIOGRAPHIES}

M.Sc. Salla Lind is a Research Scientist at VTT. She received her Master's degree from Tampere University of Technology in 2001. Currently M.Sc. Lind is finalizing her Ph.D. thesis on safety risk management in industrial maintenance. M.Sc. Lind's scientific interests include safety and human factors in industrial workplaces. Her email address is $<$ salla(dot)lind(at)vtt(dot)fi $>$.

Dr. Boris Krassi is a Research Scientist of HumanMachine Systems team. He has attained nine years of experience in implementing and managing EU and national $\mathrm{R} \& \mathrm{D}$ projects in ICT, dynamic virtual prototyping, control and robotics. His e-mail address is $<$ boris(dot)krassi(at)vtt(dot)fi $>$.

M.Sc. Juhani Viitaniemi is Senior Research Scientist at VTT. He holds M.Sc. degree in machine design from Tampere University of Technology. M.Sc. Viitaniemi has gained over 20 years of experience and he is currently working in three international and four national projects. M.Sc. Viitaniemi has over 30 scientific publications. M.Sc. Juhani Viitaniemi's scientific interest include methods and tools for research and development to gain simulation, VEs and digital human models in promotion of ergonomics, usability and safety concerning workplace activities focused on human-technology interactions. His e-mail address is $<$ juhani(dot)viitaniemi(at)vtt(dot)fi $>$.

B.Sc. Sauli Kiviranta, Research Engineer of HumanMachine Systems, is an expert on computer graphics and development of immersive multimodal virtual environments. His e-mail address is $<$ sauli(dot)kiviranta(at)vtt(dot)fi $>$.
M.Sc. Juhani Heilala is a senior research scientist at VTT, the Technical Research Centre of Finland. He has an M.Sc from the Department of Mechanical Engineering at Oulu University. He has 20 years' experience in robotics and production system development. His current research interest includes expanding simulation and modeling from system design and analysis methods to simulation-based manufacturing operation planning and integration of production system simulation with other analysis methods. His e-mail address is <juhani(at)heilala(at)vtt(dot)fi $>$.

M.Sc. Cecilia Berlin is working towards a Ph.D. degree in Production System Ergonomics at Chalmers University of Technology in Gothenburg, Sweden. She is currently working on her thesis for the degree of Technical Licentiate. Her research interest concerns how virtual tools for ergonomics can be made dynamic and how they are used in different corporate settings. She received her M.Sc. degree in Industrial Design Engineering in 2005, also from Chalmers. Her e-mail address is $<$ cecilia(dot)berlin(at)chalmers(dot)se $>$. 